\title{
Book Review: A Billion Black Anthropocenes or None. Kathryn Yusoff. Minneapolis: University of Minnesota Press, 2018. ISBN 9781517907532
}

\author{
Antonio López ${ }^{1}$ \\ 1 John Cabot University, Rome, Italy \\ Keywords: colonialism, extractivism, white geology, black anthropocenes, anthropocene \\ https://doi.org/10.1525/001c. 27370
}

To make up for the absence of engagement with environmental issues, increasingly the Anthropocene label is getting slapped onto conferences, journal themes, and book titles to signal an ecological turn across disciplines. Triggered by the emerging alarm of looming threats of the climate crisis, extinction shock, and pandemics (among a long list of environmental dangers), this evolving environmental attention is welcome, but the careless and uncritical application of the term, Anthropocene, is perhaps less so. Worldecologist scholars Raj Patel and Jason W. Moore argue that using Anthropocene as a marker for the human-altered environment (as it is commonly conceived of in geology and in popular discourse) assigns blame to humans being humans, but misidentifies what is actually the results of particular human activities governed by the structure of capitalism. Instead, they advocate using "Capitalocene," because it's not just an economic system but "a way of organizing the relations between humans and the rest of nature" that is the source of our planetary ecological crisis (Patel and Moore 2017, 3 ). The Anthropocene equalizes the infinitesimal contributions of its primary victims - the majority of humans who did not create the planetary ecological crisis-with its main perpetrators.

Many scholars argue that slavery and the plantation system prefigure capitalism and our current global economic structure, so "Plantationocene" is a better label. As Donna Haraway explains in a 2019 interview with Le Monde, this usage "describes the devastating transformation of different types of pasturage, cultures and forests into closed, extractive plantations, which are founded on the work of slaves and other forms of work that involve exploitation, alienation and generally spatial displacement... [It reminds us that] this model of establishing plantations on a large scale preceded industrial capitalism and allowed it to develop, accumulating wealth on the back of human beings reduced to slavery" (quoted in Kodjo-Grandvaux 2020). Other terms that have been proposed-some tongue and cheek-include Chthulucene, Petrolcene, Plasticene, Misanthropocene, and Anthrobscene. Macarena Gómez-Barris

\footnotetext{
a Antonio López, Ph.D. has a research focus on bridging ecojustice with media literacy. His most recent book is Ecomedia Literacy: Integrating Ecology into Media Education (Routledge). Currently, he is Associate Professor of Communications and Media Studies at John Cabot University in Rome, Italy. Resources and writing are available at: https://antonio-lopez.com/
} 
prefers the term "colonial Anthropocene" (Gómez-Barris 2019) to counter colonial geology's humanistic narcissism and gaslighting that common usages of Anthropocene invoke.

What's at stake is the origin story of the Anthropocene. A homogeneous Anthropocene narrative universalizes "humanity," overlooking how the global environmental crisis is unevenly caused and its effects unequally distributed. In A Billion Back Anthropocenes or None, Kathryn Yusoff seeks to re-center the role of race in the Anthropocene debate. A professor of inhuman geography at Queen Mary University of London, she mines the sedimentation of conventional geology by drawing on critical race studies, Black feminist theory, material histories, and aesthetics. She asserts the post-racial "we" of the Anthropocene does not acknowledge "black and brown death" as the "precondition of every Anthropocene origin story" (Yusoff 2018, 66). It also obfuscates the historical legacy of slavery as necessary for gold and silver mining, and the intimate relationship between geological narratives and the erasure of humanness that resulted from colonialism; "White Geology" denies its imperial origins and how it remains complicit in neo-colonial extractivism. Indeed, if you read the Wikipedia entry on geology, one line sticks out: "In practical terms, geology is important for mineral and hydrocarbon exploration and exploitation, evaluating water resources, understanding of natural hazards, the remediation of environmental problems, and providing insights into past climate change" (Wikipedia 2020). You'll note the conflicting purposes between mineral and hydrocarbon exploration and environmental remediation. When it comes to extractive and neo-colonial mega-projects, geologists are likely to arrive even before the military or police come to evict people off their lands. In this sense, Yusoff asserts that geology is colonial world-making, with world-breaking as its externality. Connecting the racist history of geology with environmental degradation, Yusoff quotes W.E.B. Du Bois, who defined Whiteness as "ownership of the Earth for ever and ever" (qtd. in Yusoff 2018, 26).

Yusoff raises questions regarding the so-called "golden spikes" that geologists are debating to mark the beginning of the Anthropocene (such as the initial European "exchange" of flora and fauna in the Americas, invention of the steam engine, or the first nuclear weapons test). Subsequently, she rejects the Capitalocene concept, noting that it plays too much into the narrative of the industrial revolution as a golden spike of the Anthropocene. Rather, we have to go farther back to its dehumanizing origins: "Because all the proffered Golden Spikes impale flesh, they are sites of violence enacted on the integrity of subjectivity, corporeality, and territoriality. Origination is displacement" (Yusoff 2018, 60, emphasis in original). Yusoff suggests that the advent of the European slave trade in Africa marks the true golden spike, which concurs with Patel and Moore's claim that capitalism derives from the invention of the plantation system in Portugal's island colony of Madeira in the mid-16th century. Yusoff writes, "The birth of racial subject is tied to colonialism and the 
conquest of space and the codification of geology as property and properties. Thereby geologic resources and bodily resources (or racialized slavery) share a natal moment” (Yusoff 2018, 58).

"A billion black Anthropocenes" refers to the erasure of humanness from the countless forgotten extinctions and deaths of black and indigenous peoples. Yusoff thereby contests the liberal narrative that the Anthropocene is about concerns for the future: "the Anthropocene is configured in a future tense rather than in recognition of the extinctions already undergone by black and indigenous peoples. Following in the wake of humanism, the production of the Anthropocene is predicated on Whiteness as the color of universality" (Yusoff 2018, 51). Scholarship to resurrect this history is urgent, for, in the words of Gómez-Barris, it's an "effort to push against the grain of... a dominant climate change knowledge formation, prevalent in the mass media as well as in certain quarters of the disciplining academy.... For those of us working on histories of race, colonialism, and dispossession and in relation to the environmental humanities we might ask how does placing Indigeneity and Blackness at the center of our analysis both ground its consequences and remake how we understand past, present, and impending catastrophe” (Gómez-Barris 2019).

Environmental concerns of geologists include climate impacts, such as melting ice (which changes weight distribution on the tectonic plates), and the effects of mega projects and infrastructure like dam-building, mining, roadbuilding, landfills, and deforestation on geological formations. But this is only part of the story. Instead, Yusoff addresses geology's role in the history of slavery and forced displacement. The establishment of race as a classification to justify slavery goes hand-in-hand with the categorization of natural resources for exploitation. Blackness and minerals simultaneously become empty signifiers for capital accumulation and value: "Bodies become gold, emptied of the sign of the human, reinvested with the signification of units of energy and properties of extraction" (Yusoff 2018, 83). Furthermore, "Both the enslaved and minerals are recognized as possessing certain properties or qualities, namely, energy, reproducibility, and transformation" (Yusoff 2018, 70). The "double dispossession" of humanness and land leads to the loss of place, space, and land, and the production of non-citizenship, non-being, and inhumanity. The current "problem" of migration results from these interrelated histories, but here problem is in quotes because the way it is defined in popular discourse is another form of exclusion. While migration to Europe and North America gets the most media attention, internal migration and migration across Africa (and other regions in the world) is a far greater crisis. Given that the loss of land is a primary driver of migration, the movement of people as the climate changes is directly connected to geology's role in displacing people from their original lands, producing a violent form of biopolitics. 
The connection for ecomedia scholars should be clear. The minerals extracted for our gadgets are tied to a system that emerged from a long, sordid history of mining, resource extraction, ecological devastation, and human abuse and displacement. The current distribution of wealth and inequality, and the global infrastructure and its supply chains that make information and communication technology (ICT) possible, would not exist without the foundation of chattel slavery and extracted mineral wealth. Noting historical continuity, Jack Qiu draws parallels with the original transatlantic slave trade and current labor practices in China, asserting that just as European desire for sugar drove slavery, gadget addiction drives the system of human rights abuses that results from tech's production chain (Qiu 2016). Recall that mining is still a prerequisite for ICTs, such as rare earth minerals that drive conflicts in regions like the Congo and lithium production for batteries that has generated political instability in Bolivia. The current materialist turn in media studies has also pointed back to geology. Jussi Parikka's A Geology of Media reminds us that before data mining, there is earth mining: "Geology refers to the affordances that enable digital media to exist as a materially complex and politically economically mediated realm of production and process: a metallic materiality that links the earth to the media technological" (Parikka 2015, 44). As applied to ecomedia, Sean Cubitt has put forward a decolonial perspective that focuses on enclosure and the various ways (often mundane) that ICTs drive environmental destruction (Cubitt 2014). Not only is our current chain of gadget production a continuation of the same system and grammar of White Geology, but it necessitates an ecojustice response that recognizes how wealthy nations and their institutions owe biodiversity debt, and are obliged to engage in reparations, restoration, and land reform.

The relationship between earth sciences and human geography is what Yusoff calls "geo-social formations"; her project is to "de-sediment" the social life of geology that has led to anti-Black epistemologies. If geology expresses white liberal desire while erasing black and brown bodies, then the uncritical use of the term Anthropocene totalizes the effects of colonialism while simultaneously erasing its origins by reproducing the very problem it's trying to name. For this reason, we should acknowledge that the colonial Anthropocene better represents a historical legacy that demands correcting. A cynical reading of the common use of Anthropocene is that certain academic disciplines are waking up to the environmental crisis spawned by extractivism without having to actually confront its bloody and dehumanizing history. Anthropocene has become simple shorthand for the impact of anthropogenic industrialization on the world, but, "There can be no address of the planetary failures of modernism or its master-subject, Man, without a commitment to overcoming extractive colonialism” (Yusoff 2018, 61).

So, though re-framing the Anthropocene's origins unearths its genocidal past, it also informs how we respond to the present: "If the imagination of planetary peril coerces an ideal of 'we,' it only does so when the entrappings of late 
liberalism become threatened. This 'we' negates all responsibility for how the wealth of that geology was built off the subtending strata of indigenous genocide and erasure, slavery and carceral labor, and evades what that accumulation of wealth still makes possible in the present-lest 'we' forget that the economies of geology still largely regulate geopolitics and modes of naturalizing, formalizing, and operationalizing dispossession and ongoing settler colonialism” (Yusoff 2018, 106). 


\section{REFERENCES}

Cubitt, Sean. 2014. “Decolonizing Ecomedia.” Cultural Politics 10 (3): 275-86. https://doi.org/ $10.1215 / 17432197-2795669$.

Gómez-Barris, Macarena. 2019. "The Colonial Anthropocene: Damage, Remapping, and Resurgent Resources." Antipode Online, March 19, 2019. https://antipodeonline.org/2019/03/19/thecolonial-anthropocene/.

Kodjo-Grandvaux, Séverine. 2020. "Colonialism, The Hidden Cause Of Our Environmental Crisis." Worldcrunch, February 14, 2020. https://worldcrunch.com/culture-society/colonialism-thehidden-cause-of-our-environmental-crisis.

Parikka, Jussi. 2015. A Geology of Media. Minneapolis: University of Minnesota Press. https://doi.org/10.5749/minnesota/9780816695515.001.0001.

Patel, Raj, and Jason W. Moore. 2017. A History of the World in Seven Cheap Things: A Guide to Capitalism, Nature, and the Future of the Planet. Oakland: University of California Press.

Qiu, Jack Linchuan. 2016. Goodbye iSlave: A Manifesto for Digital Abolition. Champaign: University of Illinois Press. https://doi.org/10.5406/illinois/9780252040627.001.0001.

Wikipedia. 2020. “Geology.” https://en.wikipedia.org/w/ index.php? title $=$ Geology\&oldid $=947806269$.

Yusoff, Kathryn. 2018. A Billion Black Anthropocenes or None. Minneapolis: University of Minnesota Press. https://doi.org/10.5749/9781452962054. 